\title{
BMJ Open Engaging migrants and other stakeholders to improve communication in cross-cultural consultation in primary care: a theoretically informed participatory study
}

Christos Lionis, ${ }^{1}$ Maria Papadakaki, ${ }^{1,2}$ Aristoula Saridaki, ${ }^{1}$ Christopher Dowrick, ${ }^{3}$ Catherine A O'Donnell, ${ }^{4}$ Frances S Mair, ${ }^{4}$ Maria van den Muijsenbergh, ${ }^{5,6}$ Nicola Burns, ${ }^{4,7}$ Tomas de Brún, ${ }^{8}$ Mary O’Reilly de Brún, ${ }^{8}$ Evelyn van Weel-Baumgarten, ${ }^{5}$ Wolfgang Spiegel, ${ }^{9}$ Anne MacFarlane ${ }^{10}$

To cite: Lionis C,

Papadakaki M, Saridaki A, et al. Engaging migrants and other stakeholders to improve communication in crosscultural consultation in primary care: a theoretically informed participatory study. BMJ Open 2016;6:e010822. doi:10.1136/bmjopen-2015010822

- Prepublication history for this paper is available online. To view these files please visit the journal online (http://dx.doi.org/10.1136/ bmjopen-2015-010822).

Received 18 December 2015 Revised 17 April 2016 Accepted 11 May 2016

CrossMark

For numbered affiliations see end of article.

Correspondence to Professor Christos Lionis; ionis@galinos.med.uoc.gr

\section{ABSTRACT}

Objectives: Guidelines and training initiatives (G/TIs) are available to support communication in crosscultural consultations but are rarely implemented in routine practice in primary care. As part of the European Union RESTORE project, our objective was to explore whether the available $\mathrm{G} / \mathrm{Tls}$ make sense to migrants and other key stakeholders and whether they could collectively choose $\mathrm{G} / \mathrm{TI}$ and engage in their implementation in primary care settings.

Setting: As part of a comparative analysis of 5 linked qualitative case studies, we used purposeful and snowball sampling to recruit migrants and other key stakeholders in primary care settings in Austria, England, Greece, Ireland and the Netherlands.

Participants: A total of 78 stakeholders participated in the study (Austria 15, England 9, Ireland 11, Greece 16 , Netherlands 27), covering a range of groups (migrants, general practitioners, nurses, administrative staff, interpreters, health service planners).

Primary and secondary outcome measures: We combined Normalisation Process Theory (NPT) and Participatory Learning and Action (PLA) research to conduct a series of PLA style focus groups. Using a standardised protocol, stakeholders' discussions about a set of $\mathrm{G} / \mathrm{TIs}$ were recorded on PLA commentary charts and their selection process was recorded through a PLA direct-ranking technique. We performed inductive and deductive thematic analysis to investigate sensemaking and engagement with the G/TIs.

Results: The need for new ways of working was strongly endorsed by most stakeholders. Stakeholders considered that they were the right people to drive the work forward and were keen to enrol others to support the implementation work. This was evidenced by the democratic selection by stakeholders in each setting of one $\mathrm{G} / \mathrm{TI}$ as a local implementation project.

Conclusions: This theoretically informed participatory approach used across 5 countries with diverse healthcare systems could be used in other settings to

\section{Strengths and limitations of this study}

- The use of Participatory Learning and Action approaches promoted an atmosphere that gave equal power to all participants during fieldwork sessions and was particularly helpful in increasing migrants' engagement and participation with the process.

- Normalisation Process Theory (NPT) served as an appropriate theoretical framework to examine the emergent data and to identify possible gaps in the data.

- Beliefs and opinions of people with different sociocultural status and educational background were equally valued and interpreted within the framework provided by NPT.

- The voice of undocumented migrants was absent from our stakeholder groups and could have provided additional insights.

- The generalisability of findings is limited because a qualitative case study approach was used but the use of NPT provides insight into transferrable issues across country settings.

establish positive conditions for the start of implementation journeys for $\mathrm{G} / \mathrm{TIs}$ to improve healthcare for migrants.

\section{INTRODUCTION}

The degree to which the patient feels understood and accepted is a vital ingredient in the building of a trusting relationship between themselves and their doctor. ${ }^{1}{ }^{2}$ Relationship building in cross-cultural consultations, where migrants and doctors have different language and cultural backgrounds, 
has specific challenges. Thus, international organisations have called for healthcare to be provided in a culturally appropriate way. ${ }^{2}$

Despite the availability of guidelines and training initiatives $(\mathrm{G} / \mathrm{TIs})$ that promote the use of trained healthcare providers and interpreters to promote culturally appropriate communication in primary healthcare, they are not routinely used in day-to-day practice. ${ }^{1}{ }^{3}$ Instead, across international settings, healthcare providers lack training in cultural competence and there is a reliance on family members and bilingual staff as interpreters or mediators with well-documented negative consequences for migrants and service providers. ${ }^{1}{ }^{3-6}$

There is growing evidence about why the implementation of complex interventions such as G/TIs can prove difficult. For example, a recent review of studies of barriers to implementation of clinical practice guidelines found that the most frequently identified groupings of barriers were support/resource barriers, cognitive/ behavioural barriers, healthcare professional/physician barriers, system/process barriers and attitudinal/ rational-emotive barriers. ${ }^{6}$ Most importantly, physicians seem to be concerned that guidelines are not evidencebased, not relevant to their patient population or too complex, and consequently they simply do not agree with the guideline recommendations. ${ }^{7-11}$ Furthermore, guidelines that do not meet user requirements with regard to assumptions of their existing expertise, knowledge content and integration with workflow may not be readily adopted. ${ }^{12}$ To address some of these concerns, participatory approaches to guideline generation are recommended to unite diverse stakeholders to jointly set the agenda for practice improvement and to ensure the suitability of intervention design and the validity of guidelines for implementation in specific contexts as well as to increase the likelihood of 'buy in' to drive their implementation forward in practice settings. ${ }^{13-15}$

In the field of research about cross-cultural consultations, there is expanding knowledge about key problems and dynamics, for example, different stakeholders' experiences of interpreters, the impact of informal strategies for managing language and cultural barriers on clinical care, issues of trust with interpreted consultations and the need for proper certification in community interpreting. ${ }^{16-20}$ Yet, few studies have considered the specifics of implementing G/TIs to improve communication in cross-cultural consultations. The available research is about implementing the use of interpreters in primary care in the UK, ${ }^{3}$ Ireland (IRL) ${ }^{21}$ and Sweden. ${ }^{22}$ These studies offer valuable descriptions of barriers to implementation: the tremendous challenges of organising and enacting triadic consultations in busy general practice environments, ${ }^{3}{ }^{21}{ }^{22}$ the problematic lack of training for healthcare providers to work with interpreters and the poor availability of trained interpreters to provide high-quality services. ${ }^{21}{ }^{22}$ However, these studies focused primarily on the practical work of implementation into daily practice rather than stakeholders' conceptualisation of, or engagement in, the intervention. These are known to be important influences on implementation processes and warrant careful investigation. ${ }^{23-25}$

A recent 4-year European Union (EU) FP-7 projectRESTORE (REsearch into implementation STrategies to support patients of different ORigins and language background in a variety of European primary care settings project in migrant health) was directed at optimising delivery of primary healthcare to EU citizens who are migrants and experience language and cultural barriers in primary care settings. ${ }^{126}$ In RESTORE, our overall aim was to investigate and support the implementation of G/TIs in primary care. We used Normalisation Process Theory (NPT) as our theoretical framework to investigate levers and barriers to implementation of relevant G/TIs. NPT focuses on the social processes in implementation and the work that stakeholders have to do, individually and collectively, to make an intervention work in practice. ${ }^{27}$ Unlike other theories ${ }^{28}{ }^{29}$ it has been derived from empirical generalisations developed within studies of implementation and integration processes in mainstream healthcare. ${ }^{30}$

NPT describes four types of implementation work that relate to understanding, engagement enactment and appraisal (table 1). The first two constructs relating to understanding (coherence/sensemaking) and engagement (cognitive participation/engagement) were the primary focus of our research at the start of RESTORE and are the primary focus of this paper. To the best of our knowledge, this is one of the first studies to explore these important forms of implementation work prospectively and at the outset of a participatory implementation journey. In this paper, our research question is if migrants and other key stakeholders make sense of the available G/TIs and can they choose one and engage with its implementation in their local primary care setting?

\section{METHODS}

\section{Study design}

We conducted a qualitative case study in five European primary care settings informed by Participatory

Table 1 Normalisation Process Theory constructs

\begin{tabular}{|c|c|}
\hline Construct & What it addresses \\
\hline Coherence & $\begin{array}{l}\text { Can those involved in the } \\
\text { implementation make sense of it? }\end{array}$ \\
\hline $\begin{array}{l}\text { Cognitive } \\
\text { participation }\end{array}$ & $\begin{array}{l}\text { Can those involved in the } \\
\text { implementation maintain their } \\
\text { involvement and get others involved } \\
\text { and engaged? }\end{array}$ \\
\hline Collective action & $\begin{array}{l}\text { What has to be done to make the } \\
\text { intervention being implemented work in } \\
\text { routine practice? }\end{array}$ \\
\hline $\begin{array}{l}\text { Reflexive } \\
\text { monitoring }\end{array}$ & $\begin{array}{l}\text { How can the intervention be monitored } \\
\text { and evaluated? Can it be redesigned? }\end{array}$ \\
\hline
\end{tabular}


Learning and Action (PLA) research. PLA is a practical, adaptive research strategy that enables diverse groups and individuals to learn, work and act together in a cooperative manner, to focus on issues of joint concern, identify challenges and generate positive responses in a collaborative and democratic manner. ${ }^{31}$ The iterative and organic nature of PLA encourages diverse stakeholders to engage in cycles of research, coanalysis, reflection and evaluation over time. The aim is to use this 'PLA-brokered dialogue' to create a level playing field, where all perspectives count, and the knowledge embedded in them is shared and enhanced 'around the stakeholder table'. As mentioned earlier, this is in line with recommendations for implementation of $\mathrm{G} / \mathrm{TIs}^{32-34}$ and it is also in line with current policy imperatives prioritising patient and public involvement in research. ${ }^{35} 36$

\section{Ethical approval}

With ethical approval from the appropriate national bodies, we conducted fieldwork in five European settings: Ireland, England, the Netherlands, Austria and Greece. The Irish setting was applicable for approval, England (protocol number UoL0000671), the Netherlands (protocol number 2010/436), Austria (protocol number 1081/2012) and Greece (protocol number 8297/ 20.09.2010). In addition, Scotland provided G/TIs but did not participate in the implementation research itself. The information we present below is relevant across all sites unless otherwise specified.

\section{Sampling and recruitment}

For the needs of the sample selection, a geographically defined area (district) was selected in each partner country. Selection was pragmatic, based on proximity to the research teams, to facilitate data collection and knowledge of groups working in the district. Community organisations and agencies, active in migrant health, were then identified within each area. ${ }^{37}$ Eligible organisations/agencies were those involved in primary healthcare planning and delivery (eg, healthcare centres, regional health authorities) as well as those addressing migrant health issues (eg, non-governmental organisations focused on migrants). Details of this sampling process are described in more detail in de Brún et al. ${ }^{38}$ Following the principles of snowball sampling, this initially involved accessing networks already known to research teams in each country, rippling outwards from these to wider networks of linked colleagues and agencies. For example, one agency recommended information on another organisation that addressed migrant health issues.

The focus was to identify individuals who were decision-makers (eg, health authority service planners and policymakers), service providers (eg, general practitioners (GPs), primary care staff, community interpreters) or service users (ie, migrants using local primary care services). ${ }^{37}$ Recruited participants are referred to as 'stakeholders' in this paper.

\section{Procedures}

In each setting, data were generated using PLA style focus groups (ie, focus groups which were designed to encourage the appropriate dynamics for a PLA-brokered dialogue between stakeholders, in particular fostering an atmosphere of equality and equity, ensuring that all participants were fully involved in data generation). These were facilitated by RESTORE researchers who had been extensively trained in NPT and PLA. The researchers, both male and female, had different backgrounds, such as social work, sociology, anthropology, public health and general practice. In some cases, the researchers knew the stakeholders because of working together on previous research projects.

To ensure quality and consistency of PLA fieldwork across settings, each PLA style focus group was facilitated by two or three researchers and a standard protocol was employed. The protocol included generic information to share with stakeholders about the RESTORE multicountry study, written summaries of a set of relevant $\mathrm{G} /$ TIs for each setting that had been identified in a mapping process,${ }^{38}$ guidance on the process of sharing and assessing G/TIs with local stakeholders with PLA resources, handouts and checklists for the PLA techniques being used. The use of a standard protocol also meant that comparable data were generated across research sites. All PLA style focus groups were conducted in the native language of the country involved.

In particular, the following steps were taken in data generation:

Stakeholders were presented with summary information about the set of G/TIs that had been identified earlier in RESTORE using NPT for their local setting. ${ }^{38}$ A brief description of the G/TIs presented in each setting can be seen in table 2 and a fuller description is available elsewhere. ${ }^{38}$

Stakeholders were asked open-ended questions about their views on the $\mathrm{G} / \mathrm{TIs}$ and encouraged to have a dialogue with each other about them with a view to finding one that could be implemented in their local setting. We employed NPT constructs throughout this dialogue to stay alert to the match (or not) between the nature of the work being discussed and progressed by stakeholders and NPT's four constructs (see table 1), paying particular attention to whether stakeholders could make sense of the available G/TIs (coherence) and their level of engagement with one as an implementation project to take forward (cognitive participation).

A PLA technique was then used that allowed stakeholders to generate a 'commentary chart' for the G/TIs that they were discussing. 'commentary charts' are teamgenerated records on flip charts used to record key comments from stakeholders' discussions of each G/TI to facilitate learning between stakeholders about their various perspectives (figure 1). We had three categories of each 'commentary chart': (1) 'positive' aspects of the G/TI being discussed; (2) 'negative' aspects of the G/TI being discussed and (3) 'questions to be checked out'. 
Table 2 Characteristics of $\mathrm{G} / \mathrm{Tl}$ s selected for the implementation projects

\begin{tabular}{|c|c|c|}
\hline Country & Title & Aim of $\mathrm{G} / \mathrm{TI}$ \\
\hline Ireland & $\begin{array}{l}\text { Working with an interpreter is easy: self-directed } \\
\text { training package for health professionals }\end{array}$ & $\begin{array}{l}\text { To support the development of a national intercultural } \\
\text { health strategy where issues of language, culture and } \\
\text { communication are highlighted. }\end{array}$ \\
\hline $\begin{array}{l}\text { The } \\
\text { Netherlands }\end{array}$ & $\begin{array}{l}\text { "Did I explain it clearly?" How to communicate with } \\
\text { migrants with lower education and less command of } \\
\text { the Dutch language }\end{array}$ & $\begin{array}{l}\text { Providing information and advice for healthcare } \\
\text { workers communicating with migrant patients with } \\
\text { lower educational levels and command of the Dutch } \\
\text { language. Helping migrant patients to understand the } \\
\text { information provided, and enabling them to work with } \\
\text { the advice provided. }\end{array}$ \\
\hline Greece & $\begin{array}{l}\text { Guidance for communication in cross-cultural general } \\
\text { practice consultations }\end{array}$ & $\begin{array}{l}\text { To allow migrants and other stakeholders the } \\
\text { opportunity to determine what is 'best practice' for } \\
\text { supporting communication in cross-cultural general } \\
\text { practice consultations. }\end{array}$ \\
\hline England & Ears of Babel. Culturally sensitive primary health care & $\begin{array}{l}\text { To improve GPs' knowledge about how diseases are } \\
\text { experienced and expressed among different ethnic } \\
\text { groups and their competencies in breaking bad news } \\
\text { to migrant patients and their families. }\end{array}$ \\
\hline Austria & $\begin{array}{l}\text { No G/TI was found to be suitable for Austria. } \\
\text { Therefore, the Austrian training initiative } \\
\text { 'Cross-cultural competencies for general practitioners' } \\
\text { was developed and implemented } \\
\text { 'New European migrants and the NHS: learning from } \\
\text { each other, manual for trainers, first edition February } \\
2009 \text { ', NHS Lothian, Dermot Gorman' was used as a } \\
\text { resource for educational principles and materials }\end{array}$ & $\begin{array}{l}\text { Aimed at experienced GPs, the Austrian TI consists } \\
\text { of a basic module to enhance cross-cultural } \\
\text { competencies for GPs in an overall 20-hour } \\
\text { intervention. The format was so chosen that } \\
\text { practising GPs can manage to participate without } \\
\text { having to close their single-handed practices. } \\
\text { To educate and equip the healthcare staff with } \\
\text { confidence to deal with cultural differences in } \\
\text { healthcare settings. }\end{array}$ \\
\hline
\end{tabular}

The purpose of the 'commentary charts' was twofold. First, they provided a visual summary of stakeholders' discussions. This was a valuable way for researchers and stakeholders alike to remember the full details of their views. Second, the commentary charts were able to 'travel' between focus groups to share and enhance knowledge around the stakeholder group even if they were not physically present together. This was important because, while the ideal would be to have the same composition of stakeholders present at every PLA style focus group, we anticipated that this would be difficult to achieve in practice. The commentary charts were designed as a useful method to keep stakeholders informed about the ongoing dialogue in their group. For example, a 'commentary chart' completed by stakeholders in the Greek setting (eg, GPs, policy planners, primary care nurses) was brought along by the researcher the following week to different stakeholder groups (eg, migrant service users, social worker) who were not able to make it to the focus group the preceding week. In this way, information was shared across all the groups of stakeholders in its original form.

Once stakeholders had completed their discussions about their G/TIs and reviewed their PLA 'commentary charts', we employed a PLA technique to enable stakeholders to work together and democratically select one $\mathrm{G} / \mathrm{TI}$ as the implementation project for their setting. 'Direct ranking' is a PLA technique designed to enable a group of stakeholders to indicate priorities or preferences as part of a democratic decision-making process. 'Direct ranking' engages stakeholders' in an analytical decision-making process that is transparent and gives an equal voice and vote to all stakeholders (figure 2). The numbers on the direct ranking chart represent the number of votes each stakeholder placed on each G/TI. This has been used successfully in previous studies with migrants and other stakeholders. ${ }^{36}$

\section{Data analysis}

Three steps of analysis were followed:

First, in keeping with principles of PLA, ${ }^{2}{ }^{39}$ researchers and stakeholders conducted 'on the spot' coanalysis of data recorded on 'commentary charts' and 'direct ranking' charts during PLA style focus groups. This analysis followed the principles of a simple deductive analysis whereby emergent data were coded as either a 'positive' (eg, Ireland 'telephone interpreting could work very well in the GP setting if doctors had access to reliable telephone interpreting service') or negative comment (eg, Ireland 'In Irish context is almost impossible to implement (interpreters)') or a query that needed to be followed up on (eg, Ireland (Scottish training initiative) 'is geared to National Health Service so will there be problems in the Irish context?').

Coanalysis was managed by the trained PLA researchers through paying active attention to stakeholders' contributions to identify shared and differential views within 


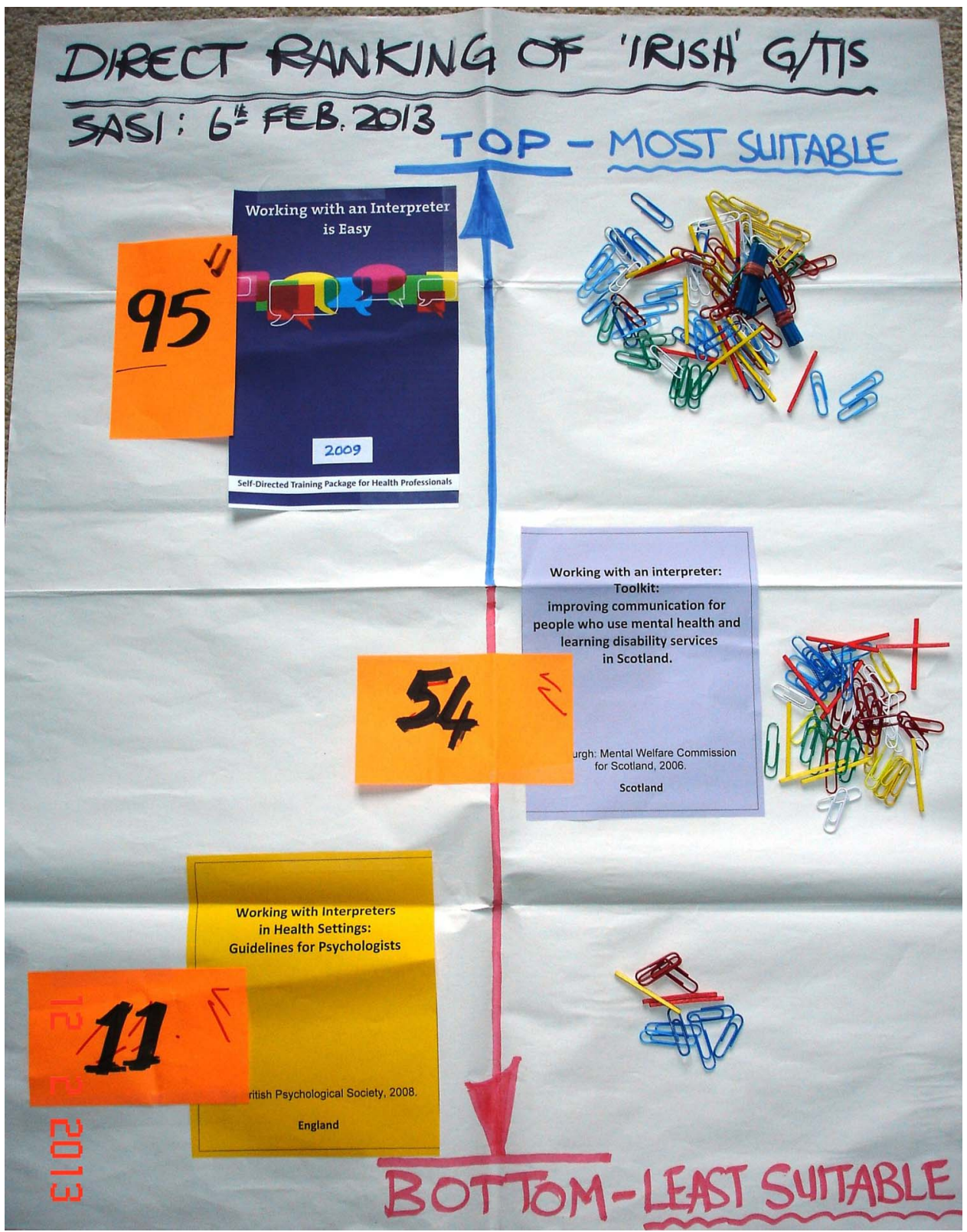

Figure 1 Commentary chart-Ireland. G/TIs, guidelines and training initiatives. SASI as noted on the chart was titled as the second phase of fieldwork.

the stakeholder group as well as by confirming/disconfirming views about data interpretation. All PLA sessions were audiotaped and processed anonymously and transcribed verbatim.

Second, the university-based researchers in the five study sites reviewed the PLA charts and the transcripts of the PLA sessions in our individual research teams, using the principles of a deductive thematic analysis informed by NPT theory. ${ }^{40}$ The purpose of the review process was to examine the emergent data and consider their resonance with the Coherence and Cognitive Participation (table 3) We then synthesised data about key promoters and inhibitors to sensemaking and engagement work within and across settings.

Finally, each team prepared a detailed narrative report using standardised headings based on NPT's constructs to facilitate cross-country analysis. For this, teams collectively mapped the emergent findings from the thematic analysis onto the four NPT constructs; where data were generated in languages other than English, the Dutch, Austrian and Greek teams translated material into English for the narrative report. The translation was conducted by one researcher and checked by a second researcher in these teams for consistency. A comparative analysis of these English language reports was led by the NPT leads (AM, $\mathrm{CAO}, \mathrm{FSM}$ and $\mathrm{CD}$ ) in close consultation with all consortium members. This analysis was also conducted following the principles of a deductive framework analysis using a set of NPT sensitising questions for coherence and cognitive participation (see table 3).

In terms of rigour, throughout each stage of our analysis, we critically assessed if there were any gaps in the 


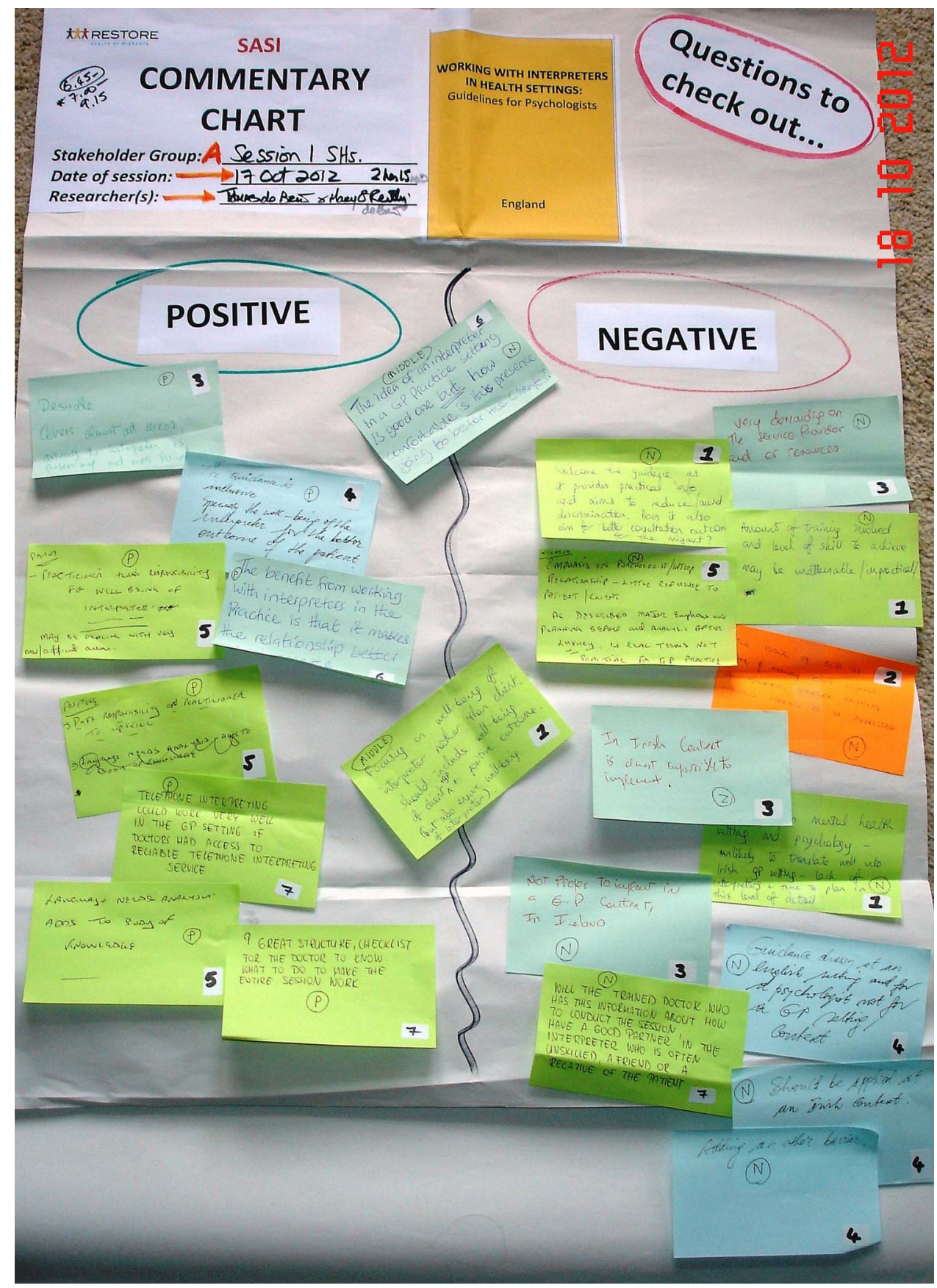

Figure 2 Direct Ranking result - Ireland. SASI as noted on the chart was titled as the second phase of fieldwork.

data versus the a priori themes. We also critically analysed whether the other two NPT constructs (collective action and reflexive monitoring) were discussed or not and whether any important issues were identified that fell outside the a priori themes. This was particularly important for our NPT analysis as we wanted to assess its utility across international settings.

Theoretical saturation was considered by examining the points at which no new ideas were being generated. This was determined by (1) stakeholders' agreement that they had completed their discussions that were being recorded on the PLA 'commentary charts' and the 'direct ranking' process, (2) the solution of arising queries from stakeholders about the G/TIs they examined, and (3) the researchers' agreement that the NPT review was complete and that all data had been accounted for.

Successful completion of these tasks produced confidence that the exploration of $\mathrm{G} / \mathrm{TIs}$ had been exhausted and that sufficient data about the process and outcomes of the decision-making work had been generated.

\section{RESULTS}

Participants' profile

A total of 304 governmental and non-governmental agencies/organisations in Austria $(\mathrm{n}=59)$, England 


\begin{tabular}{|c|c|}
\hline Construct & NPT sensitising questions for guidelines/training initiatives \\
\hline Coherence & $\begin{array}{l}\text { How do stakeholders conceptualise (make sense of) the guideline/training initiative in terms of their } \\
\text { role, content and applicability? }\end{array}$ \\
\hline Differentiation & $\begin{array}{l}\text { Can stakeholders differentiate the way of working proposed in the guideline/training initiative from } \\
\text { their current way of working? }\end{array}$ \\
\hline $\begin{array}{l}\text { Communal } \\
\text { specification }\end{array}$ & $\begin{array}{l}\text { Can stakeholders build up a shared understanding of the aims, objectives and expected benefits of } \\
\text { the guideline/training initiative? }\end{array}$ \\
\hline $\begin{array}{l}\text { Individual } \\
\text { specification }\end{array}$ & $\begin{array}{l}\text { Can individual stakeholders 'make sense' of the work that implementation of the guideline/training } \\
\text { initiative would create for them in their routine work? }\end{array}$ \\
\hline Internalisation & $\begin{array}{l}\text { Can stakeholders grasp the potential value, benefits and importance of the guideline/training } \\
\text { initiative? }\end{array}$ \\
\hline Cognitive participation & $\begin{array}{l}\text { Do stakeholders engage with the new guideline/training initiative, and if yes, what roles do they take } \\
\text { on (or not) to promote their implementation? }\end{array}$ \\
\hline Initiation & $\begin{array}{l}\text { Are stakeholders able and willing to drive the implementation of the guideline/training initiative } \\
\text { forward and get others involved in the new practices? }\end{array}$ \\
\hline Legitimation & $\begin{array}{l}\text { Do stakeholders believe it is right for them to be involved with the guideline/training initiative and that } \\
\text { they can make a useful contribution to its implementation? }\end{array}$ \\
\hline Enrolment & $\begin{array}{l}\text { Do stakeholders have the capacity and willingness to organise themselves in order to collectively } \\
\text { contribute to the work involved in implementing the new guideline/training initiative? }\end{array}$ \\
\hline
\end{tabular}

$(n=27)$, Greece $(n=43)$, Ireland $(n=50)$ and the Netherlands $(n=125)$ were identified to be eligible for RESTORE. From this, 78 stakeholders agreed to participate (Austria 15, England 9, Greece 16, Ireland 11, Netherlands 27) and were involved in the stage of fieldwork reported in this paper. The stakeholders represented a broad range of groups as desired: migrants, GPs, nurses, administrative staff, interpreters, health service planners. In terms of the composition of individual focus groups, the repeat engagement of stakeholders was generally good and the PLA commentary charts worked well to keep stakeholders informed of developments and without disrupting the dynamics of the groups.

Table 4 shows the participants' sociodemographic characteristics.

We conducted a total of 28 PLA focus group sessions with an average of 5.6 sessions held in each field site (eg, at the health centre or university campus) from September 2012 to May 2013 (Austria 4, England 7, Ireland 5, Greece 6, Netherlands 6) with an average time of 40 min per session.

Table 5 below shows the limited set of G/TIs that were presented in each country in the PLA style focus groups and in table 6 a richer description of the participants and the characteristics of the PLA sessions can be found.

\section{RESULTS CONTINUED}

\section{Stakeholders making sense of the G/Tls (coherence)}

Across settings, stakeholders confirmed that the new ways of working recommended by the G/TIs that they examined were different from current routine practice and that this was important given the problems with the status quo, for example, using family and friends as interpreters or the lack of training among healthcare providers in cultural competence. In England, for example, stakeholders were positive that the guideline from Ireland clearly laid out the problems with informal interpreters and provided guidance about how to work with formal, trained interpreters (results are given in table 7, Q1). Likewise, stakeholders in Greece emphasised that health professionals had never received culturally sensitive training and did not routinely use interpreters in healthcare consultations (results are displayed in table 7, Q2).

There were, however, cases where stakeholders could not differentiate the way of working proposed in the G/TI from current ways of working such as in Austria and particularly for the Irish guideline that recommended for best practice the use of a formal trained interpreter is best. Yet this was difficult to implement in the Greek setting.

Stakeholders across settings considered the aims, objectives and expected benefits of the G/TI they examined. In all the partner countries, the majority of G/TIs had contextual relevance because they provided knowledge or guidance that could inform a new way of working to improve healthcare for migrants. Migrants emphasised this point (results are given in table 7, Q3 and Q4), but other stakeholders saw these potential benefits as well (results are given in table 7, Q5 and Q6). One exception was recorded in Austria-one migrant there did not see benefits of the proposed use of interpreters in the healthcare setting as they placed a higher value on privacy during consultations (results are given in table 7, Q7).

Interestingly, stakeholders in IRL were the only participant group to explicitly mention the potential benefits 
Table 4 Participants' sociodemographic characteristics

\begin{tabular}{|c|c|c|c|c|c|}
\hline & Austria & England & Greece & Ireland & Netherlands \\
\hline \multicolumn{6}{|l|}{ Gender } \\
\hline Male & 6 & 2 & 6 & 3 & 8 \\
\hline Female & 9 & 7 & 10 & 8 & 19 \\
\hline \multicolumn{6}{|l|}{ Age group } \\
\hline $18-30$ & 3 & 2 & 3 & 0 & 2 \\
\hline $31-55$ & 9 & 7 & 11 & 11 & 20 \\
\hline $56+$ & 3 & 0 & 2 & 0 & 5 \\
\hline \multicolumn{6}{|l|}{ Country of origin } \\
\hline Chile & - & - & - & 1 & - \\
\hline Congo & - & - & - & 1 & - \\
\hline Ireland & - & - & - & 3 & - \\
\hline Nigeria & - & - & - & 1 & - \\
\hline Poland & - & - & - & 1 & - \\
\hline Portugal & - & - & - & 1 & - \\
\hline Russia & - & - & - & 1 & - \\
\hline Netherlands & - & - & 1 & 1 & 22 \\
\hline Morocco & - & - & - & - & 1 \\
\hline Indonesia & - & - & - & - & 3 \\
\hline Philippines & 2 & - & - & - & 1 \\
\hline Greece & - & - & 13 & - & - \\
\hline Syria & - & 1 & 1 & - & - \\
\hline Albania & - & - & 1 & - & - \\
\hline UK & - & 6 & - & - & - \\
\hline Pakistan & - & 1 & - & - & - \\
\hline Austria & 7 & - & - & - & - \\
\hline Croatia & 2 & - & - & - & - \\
\hline Turkey & 2 & - & - & - & - \\
\hline Ghana & 1 & - & - & - & - \\
\hline Benin & 1 & - & - & - & - \\
\hline Undefined & - & 1 & - & - & - \\
\hline \multicolumn{6}{|l|}{ Stakeholder group } \\
\hline Migrant community & 8 & 7 & 2 & 8 & 8 \\
\hline Primary care doctors & 5 & 1 & 4 & 1 & 8 \\
\hline Primary care nurses & 1 & 0 & 5 & 0 & 2 \\
\hline Primary care administrative/management staff & 1 & 0 & 1 & 1 & 6 \\
\hline Interpreting community & 0 & 1 & 0 & 5 & 0 \\
\hline Health service planning and/or policy personnel & 5 & 1 & 5 & 1 & 4 \\
\hline
\end{tabular}

of a guideline for interpreters. They noted and appreciated the explicit attention in an English guideline to interpreters' well-being. This may have been due to the higher representation of community interpreters in this setting compared with others (results are given in table 7, Q8).

We found that stakeholders did consider the work that implementation of a G/TI from another country would create for them in their own setting. In the main, these deliberations concentrated on the effort that would be involved in translating and adapting a G/TI from another country-what problems would arise, for instance, in relation to addressing differences in professional qualifications (results are given in table 7, Q9) and identifying trainers (results are given in table 7 , Q10). Perhaps it would simply be too much work. This was particularly evidenced in IRL where the stakeholders felt that the work required to adapt and translate the training initiatives (TIs) for the Irish setting was too demanding and they were uncomfortable about the time and effort involved in pursuing such a goal.

Stakeholders' deliberations focused predominately on the potential value and benefits of the G/TIs they examined and it was striking that stakeholders showed clear evidence of critical thinking about them. For example, they critically analysed the mode of delivery of TIs and considered that TIs that were experiential and practical were likely to be very valuable (results are given in table 7, Q11 and Q12). TIs that could be delivered in a time-efficient and flexible manner, for instance, courses that were short or delivered by e-learning, were also considered to be highly valuable (results are given in table 7, Q13 and Q14). Interestingly, these were not necessarily 'black and white' issues. For example, in the Netherlands, stakeholders considered that the e-learning nature of a TI would make it potentially very valuable 
Table 5 Presentation of limited set of G/TIs per country

Title of G/Tls

Guidance for communication in cross-cultural general practice consultations

General practice care in a multicultural society: a guide to interpretation services \& cultural competency, Irish College of General Practitioners, Dublin

Working with an interpreter is easy: self-directed training package for health

professionals

E-learning programme intercultural care

Practical norms/guideline for use of interpreters in health care

Ears of Babel. Culturally sensitive primary health care

Ears of Babel, workshop medically unexplained symptoms and migrants (MUS)

"Did I explain it clearly?" How to communicate with migrants with lower education and less command of the Dutch language

Working with interpreters in health settings-guidelines for psychologists.

British Psychological Society, October 2008

Good practice guide to interpreting - WSPM Agape Community Project, NHS Fact

Cards

Lost in translation-advanced skills for consulting across language barriers

Improving access to healthcare for migrants: a toolkit

Working with an interpreter: toolkit improving communication for people who use

mental health or learning disability service in Scotland

New European migrants and the NHS: learning from each other, manual for

trainers, first edition February 2009', NHS Lothian, Dermot Gorman

AUS, Australia; ENG, England; G, guideline; GR, Greece; IRL, Ireland; NETH, Netherlands; TI, training initiative.

$\begin{array}{llllll}\text { G or } & & & & & \\ \text { TI } & \text { IRL } & \text { NETH } & \text { GR } & \text { ENG } & \text { AUS } \\ \text { G } & & & X & & X \\ G & & & X & & \\ & & & & & \\ & & & & & \end{array}$

$\mathrm{TI} \quad \mathrm{X}$

TI $\quad X \quad X$

G

$\mathrm{TI}$

TI

TI

$x$

$\mathrm{x}$

$\mathrm{X} \quad \mathrm{X}$

$x \quad x$

$x$

$x$

G $\quad X$

G

$x$

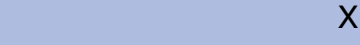

TI

TI

G

X

$x$

X

X

X

$x$ because trainees would be able to follow the training at their own pace but, on the other hand, the e-learning methods minimised the scope for experiential learning, which was highly valued and desired in TIs by the Dutch stakeholders.

Stakeholders also critically analysed the content of the G/TIs and identified gaps such as lack of attention to cultural influences on consultations involving an interpreter or scenarios where an interpreter may be refused (results are given in table 7, Q15 and Q16). Finally, stakeholders were sometimes critical of the target group of the G/TIs, usually because it was focused on care providers only rather than reception staff (results are given in table 7, Q17 and Q18) or because it was focused on one specific discipline (results are given in table 7, Q19).

\section{Stakeholders' engagement with the new G/TIs (cognitive participation)}

Stakeholders across settings spent a considerable amount of time deliberating about their scope to get others involved in the new practices recommended by the G/TIs (initiation). Typically, these deliberations were influenced by their views on the potential value of the $\mathrm{G} /$ TIs described above. The mode of delivery of TIs was considered to be key to their potential value because stakeholders were well aware of the challenges that present, especially when trying to get busy GPs on board. For example, stakeholders in England were concerned about getting GPs to commit to a full day of training and a GP stakeholder in Greece reported real concerns about fitting training into his/her schedule and (results are given in table 7, Q20 and Q21). The short nature of TIs that could be delivered in the practice setting was regarded as something that would help to get GPs involved in the Netherlands (results are given in table 7 , Q22).

Stakeholders in the English setting (results are given in table 7, Q23) reflected that while TIs may be considered important by health professionals, they may not be high enough on those professionals' priority lists for professional or practice development.

Interestingly other aspects of engagement (cognitive participation) were not discussed or recorded in the PLA commentary charts. However, in each setting, after completing their deliberations on the G/TIs and drawing on learning from sharing their views with each other, stakeholders successfully worked through the direct ranking process. The result was the democratic selection of one G/TI for each setting, which was accepted by each group as a collective decision.

Furthermore, the end point in each setting was that the majority of stakeholders in each setting confirmed that they wished to remain involved in RESTORE and drive the implementation of their selected G/TI forward. This is considered as an embodied indication that they considered it was legitimate for them to be involved in the selection of a G/TI for their local setting.

It was notable that stakeholders were particularly energised to adapt their selected G/TI so that they could address some of their concerns about it. For example, in the Netherlands, a Dutch TI was ranked first and the Dutch stakeholders clarified that they were willing to 
Table 6 Description of participants-characteristics of Participatory Learning and Action (PLA) sessions

\begin{tabular}{|c|c|c|c|c|c|}
\hline & \multicolumn{5}{|l|}{ Country } \\
\hline & Ireland & Netherlands & Greece & England & Austria \\
\hline $\begin{array}{l}\text { Number of total } \\
\text { PLA sessions }\end{array}$ & 5 & 6 & 6 & $\begin{array}{l}7 \text { ( } 4 \text { main } \\
\text { sessions, } 3 \\
\text { one-to-one } \\
\text { sessions) }\end{array}$ & 3 \\
\hline $\begin{array}{l}\text { Total number of } \\
\text { participants in } \\
\text { SASI } \\
\text { Sociodemographics } \\
\text { Gender }\end{array}$ & of stakeholder represer & tatives & 16 & 9 & 15 \\
\hline Male & 3 & 8 & 6 & 2 & 6 \\
\hline Female & 8 & 19 & 10 & 7 & 9 \\
\hline \multicolumn{6}{|l|}{ Age group } \\
\hline $18-30$ & 0 & 2 & 3 & 2 & 3 \\
\hline $31-55$ & 11 & 20 & 11 & 7 & 9 \\
\hline $56+$ & 0 & 5 & 2 & 0 & 3 \\
\hline \multicolumn{6}{|c|}{ Background (stakeholder to self-select which to answer) } \\
\hline Country of origin & $\begin{array}{l}\text { Chile }=1 \\
\text { Democratic Republic } \\
\text { of Congo=1 } \\
\text { Ireland=3 } \\
\text { Nigeria }=1 \\
\text { Poland }=1 \\
\text { Portugal=1 } \\
\text { Russia }=1 \\
\text { Netherlands }=1\end{array}$ & $\begin{array}{l}\text { Netherlands }=22 \\
\text { Morocco }=1 \\
\text { Indonesia }=3 \\
\text { Philippines }=1\end{array}$ & $\begin{array}{l}\text { Greece }=13 \\
\text { Netherlands=1 } \\
\text { Syria }=1 \\
\text { Albania=1 }\end{array}$ & $\begin{array}{l}\text { UK=6 } \\
\text { Pakistan=1 } \\
\text { Syria }=1 \\
\text { Other }=1\end{array}$ & $\begin{array}{l}\text { Austria=7 } \\
\text { Croatia=2 } \\
\text { Philippines=2 } \\
\text { Turkey=2 } \\
\text { Ghana=1 } \\
\text { Benin=1 }\end{array}$ \\
\hline Nationality & $\begin{array}{l}\text { Chilean=1 } \\
\text { Dutch=1 } \\
\text { Irish=6 } \\
\text { Polish=1 } \\
\text { Portuguese=2 }\end{array}$ & $\begin{array}{l}\text { Dutch }=24 \\
\text { Indonesian=2 } \\
\text { Philippine=1 }\end{array}$ & $\begin{array}{l}\text { Greece }=13 \\
\text { Netherlands=1 } \\
\text { Syria=1 } \\
\text { Albania=1 }\end{array}$ & $\begin{array}{l}\text { British=2 } \\
\text { British/ } \\
\text { Algerian=1 } \\
\text { British/ } \\
\text { Syrian=1 }\end{array}$ & Austrian \\
\hline Ethnicity & $\begin{array}{l}\text { No stakeholder } \\
\text { chose to respond to } \\
\text { the ethnicity } \\
\text { category }\end{array}$ & $\begin{array}{l}\text { No stakeholder chose } \\
\text { to respond to the } \\
\text { ethnicity category }\end{array}$ & $\begin{array}{l}\text { Greek=13 } \\
\text { Dutch=1 } \\
\text { Syrian=1 } \\
\text { Albanian=1 }\end{array}$ & $\begin{array}{l}\text { White }=1 \\
\text { Black British=1 } \\
\text { Arab=1 } \\
\text { Arab/ } \\
\text { British }=1\end{array}$ & $\begin{array}{l}\text { No stakeholder } \\
\text { chose to respond to } \\
\text { the ethnicity } \\
\text { category }\end{array}$ \\
\hline \multicolumn{6}{|l|}{ Stakeholder group } \\
\hline $\begin{array}{l}\text { Migrant } \\
\text { community }\end{array}$ & 5 & 7 & 2 & 7 & 3 \\
\hline $\begin{array}{l}\text { Primary care } \\
\text { doctors }\end{array}$ & 1 & 8 & 4 & 1 & 5 \\
\hline $\begin{array}{l}\text { Primary care } \\
\text { nurses }\end{array}$ & 0 & 2 & 4 & 0 & 1 \\
\hline $\begin{array}{l}\text { Primary care } \\
\text { administrative/ } \\
\text { management } \\
\text { staff }\end{array}$ & 1 & 6 & 1 & 0 & 1 \\
\hline $\begin{array}{l}\text { Interpreting } \\
\text { community }\end{array}$ & 3 & 0 & 0 & 1 & 0 \\
\hline $\begin{array}{l}\text { Health service } \\
\text { planning and/or } \\
\text { policy personnel }\end{array}$ & 1 & $\begin{array}{l}4 \text { (of which } 2 \text { health } \\
\text { insurance) }\end{array}$ & 5 & 1 & 5 \\
\hline
\end{tabular}

work on the content so that it was more suitable for a wider group of health professionals.

Finally, it is important to consider the impact of the PLA dialogue on the voting process. In IRL, as aforementioned, stakeholders felt that the work required to adapt and translate a G/TI from another country to the Irish setting would be too demanding. Their views about this were so strong that they made a decision not to include $\mathrm{G} / \mathrm{TIs}$ from other countries in their direct ranking process at all. When voting on the remaining 
Table 7 Results

\section{NPT construct}

Coherence-differentiation

G/TIs represented a new and preferred way of working

Coherence-communal specification

Recognised potential benefits of new practices recommended by $\mathrm{G} / \mathrm{TIs}$

Coherence-individual specification

Concerns about work that implementation of $\mathrm{G} / \mathrm{TI}$ from a different country

CO internalisation

Appreciation for experiential, practical training Identified gaps in $\mathrm{G} / \mathrm{T}$ Is content

Deliberations regarding target group of $\mathrm{G} / \mathrm{TI}$

\section{Illustrative quotes}

Q1

[This guideline] Includes nothing new. (AT, SH01)

Q2

This guideline is necessary in our setting as we do not receive any training on such sensitive issues for the vulnerable groups that we serve. We do not even have experience to use an interpreter during a consultation! (GR, SH07)

Q3

I think if this is introduced to health professionals it can help how they treat us. (GR, SH14)

Q4

Good, that people learn something about my home country-to better understand me. (AT, SH14)

Q5

Could improve quality of service immediately through simple tools.

(IRL, SH02)

Q6

This could raise the practice of interpreters. (ENG, SH07)

Q7

[I] want to be alone with the doctor during consultation. (AT, SH13)

Q8

Medically unexplained symptoms among migrants is one of the main themes/problems in communication with migrants. (ENG, SH12)

Q9

Would need adapting for English context rather than Irish-if there is a difference. Also qualifications section-chapter 1. (ENG, SH08)

Q10

I am not clear about how this will work, will the Dutch trainers come here-or is this simply all online? (NETH, SH02)

Q11

Very interactive session using different training methods/tools to keep the trainee interested in the course. (ENG, SH01)

Q12

The format is helpful: with actors and role plays. It is very applicable/ practical. Theory and practice are handled with at the same time.

(NETH, SH02)

Q13

Short timeframe for training is a positive, plus self-directed aspect. (IRL, $\mathrm{SH} 02)$

Q14

You can do the e-learning in your own time and at your own speed.

(NETH, SH02)

Q15

Does not focus on the cultural aspects. (IRL, SH03)

Q16

It doesn't include a heading for what to do if you are refused an interpreter. (ENG, SH01)

Q17

Is the training not open to frontline staff also, as they are the ones who have first contact with service users. (ENG, SH01)

Q18

Training does not involve rest of the practice. (NETH, SH03)

Q19

Implementation of this guideline in Ireland is very unlikely. It is too broad and specifically designed for a specialist (psychologists) practice. To me it is not workable in Irish GP context. (IRL, SH12)

Q20

Commitment required for a full day, GP's may be less likely to participate. 
Table 7 Continued

\begin{tabular}{ll}
\hline NPT construct & Illustrative quotes \\
\hline Cognitive participation & (ENG, SH02) \\
Initiation & Q21 \\
I do not have time to do this e-learning activity at home or at the practice. We \\
do not even have time to take a proper lunch break! This is not practical. \\
(GR, SH06) \\
Q22 \\
The training can be done in the practice and it consists of 1 day session \\
only. (NETH, SH134) \\
Q23 \\
Not a priority in the grand scheme of things [among GPs]. (ENG, SH08) \\
Q24 \\
There are so many technical issues to have an interpreter, how will we find a \\
certified one firstly and secondly we would need multiple interpreters for all \\
the different languages. This is difficult for Greece. (GR, SH03)
\end{tabular}

Quotations from selected stakeholders across settings. AT, Austria; ENG, England; G/TI, guideline and training initiative; GP, general practitioner; GR, Greece; IRL, Ireland; NETH, Netherlands; NPT, Normalisation Process Theory.

G/TIs, the Irish training, which was short and selfdirected, was ranked first and far higher than the Scottish training manual and the English guideline, which were more time-consuming. This results reflected the stakeholders' discussions together that they were more willing to carry out the implementation of a short and self-directed TI forward.

Conversely, despite the real concerns that the Greek stakeholders had about their capacity to drive the implementation of interpreted consultations forward in their setting because of serious concerns about whether resources would be available to provide interpreting services (results are given in table 7, Q24), the Irish guideline promoting the use of professional trained interpreters received the highest number of votes in their direct ranking process. The stakeholders selected this guideline because, after their deliberations together, they considered that it was highly relevant to their context and they reported a willingness to try to overcome a range of practical challenges (eg, lack of certified interpreters) and capacity issues (eg, lack of staff) that the financial crisis introduced to the Greek healthcare sector. While this issue of capacity was strongest in Greece, it was also featured in stakeholders' deliberations in all other settings. This reveals that stakeholders also consider issues that map onto NPT collective action, although there were relatively little data of this nature.

While there were other data relating to migration in general and some migrant health issues, there were no data about implementation of $\mathrm{G} / \mathrm{TIs}$ that fell outside NPT's constructs.

\section{DISCUSSION}

\section{Summary of key findings}

Using a combination of NPT and PLA methods, we have closely investigated important and under-researched implementation work relating to conceptualisation of, and engagement with, G/TIs to improve communication in cross-cultural consultations. We have revealed that stakeholders, including migrants across settings, could conceptualise multiple potential benefits of $\mathrm{G} / \mathrm{TIs}$ and could select one for implementation in their local setting. Furthermore, all stakeholders were able to identify ways to adapt their selection G/TIs and were willing to invest more of their time in driving forward $G / T I$ implementation.

We have demonstrated that, using participatory approaches, it is feasible and beneficial to involve migrants with other stakeholder groups at the start of implementation journeys. The current study provides valuable practical tools and methodologies that can be used in other studies to facilitate the partnership approaches between diverse stakeholders to work together to achieve their goals, implementing change for practice improvement.

\section{Comparison with previous literature}

Stakeholders in most of the partner countries commented that the proposed ways of working in the G/TIs were different from current practice. This confirms previous findings that there is a reliance on informal strategies to manage language and cultural differences in crosscultural consultations across international settings'. 3 Despite pre-existing differences either in the contextual or cultural context, there was a strong shared sense across stakeholder groups and settings that the proposed new ways of working in the G/TIs represented improvements to current practice and that the successful implementation of these G/TIs would be valuable with benefits for professionals and migrants alike. This resonates with previous studies that show that migrants and healthcare professionals are concerned to improve current practices and to reduce the use of informal strategies to support communication. ${ }^{3641}$

Stakeholders' critical analysis of the G/TIs provides important new data about how migrants and other 
stakeholders have valuable knowledge about adapting $\mathrm{G} / \mathrm{TIs}$ to make them even more suitable for user requirements. This is important because we know from the implementation science literature that $\mathrm{G} / \mathrm{TIs}$ are firmly rooted in the time and place of their production. ${ }^{42}$ Adaptations are important for increasing the chances of adoption. ${ }^{12}$ Following NPT, adaptations should enhance the potential value of the G/TIs for stakeholders even further, which in turn should enhance 'buy in', both of which should support the implementation work.

Another key finding from this study is that stakeholders in all the partner countries were clearly aware of contextual factors that may inhibit engagement with the G/TIs and may impact negatively on implementation, such as the structure and funding of the primary healthcare system. ${ }^{43}$ However, despite such contextual influences, in each setting, stakeholders did go ahead with the direct ranking and selected one G/TI as their implementation project. They all found at least one G/TI that they felt they could 'buy into' and indeed 'champion' within their networks. This suggests that stakeholders, while being critically aware of the challenges ahead, were at the same time willing to try and organise themselves to work collectively and carry out an implementation project in their local setting. There is increasing interest in the field of implementation science about the impact of contextual factors on the introduction of complex interventions in healthcare settings, ${ }^{44}$ and it will be important to determine the extent to which stakeholders' collective work in RESTORE can address the range of macro-level, meso-level and micro-level factors that impact on introducing these G/TIs into practice. This analysis is underway, drawing on all four NPT constructs, ${ }^{45}$ and will be reported separately.

The work with stakeholders was not without challenges, as stakeholders could disagree on which G/TIs were most relevant to their setting and there were debates about feasibility of implementation. This is in keeping with a review of research in the field of participatory health research ${ }^{42}$ which highlighted that disagreement was not uncommon in partnership research. Interestingly, the review found that disagreement was often an opportunity for negotiation to seek consensus, which in turn was positive for trust and respect in the stakeholder groups. This was our experience of the use of PLA and its importance towards the study. Employing a participatory mode of engagement and using visual techniques stimulated dialogue and minimised tokenism when involving the public and practitioners in this health research. ${ }^{45}$ Therefore, issues could be resolved through successful negotiation.

The implications of our findings for policy and practice are interconnected. Current policy imperatives that promote public and patient involvement can be used as leverage for securing time and resources to develop partnerships for implementing practice improvements for migrants. ${ }^{35} 36$ Our work shows that this is both feasible and beneficial. This is a particularly important finding challenging views of migrants as being 'hard to reach' or too difficult to involve in research because of crosscultural differences, which resonates with other recent research. ${ }^{47} 48$

The current implementation work has been a learning experience for research participants and stakeholders involved in the study as it provided new ways of thinking and managing decision-making collaboratively. Exchange of knowledge and expertise among stakeholders was evident throughout the current implementation work. As Jagosh et al reported, community stakeholders gained research knowledge and skills, which became assets for programme planning and implementation. ${ }^{45}$ Academic stakeholders gained capacity and competence from working with community partners, which increased their awareness of community issues and to work on attitude, knowledge and skills needed for liaising with different stakeholders.

\section{Strengths and limitations}

The key strengths of this study are the use of participatory approaches (PLA) and a robust theoretical framework (NPT) to provide a valuable conceptual framework for our work. In particular, we believe that use of PLA approaches promoted the development and creation of an atmosphere that gave equal power to all participants during fieldwork sessions and was particularly helpful in increasing migrants' participation with other stakeholders through creating a migrant-friendly environment and facilitating an unconditional dialogue. NPT was helpful in appraising the nature of stakeholders' decision-making and researchers' understanding of factors that will enhance or impede implementation. It was particularly helpful in providing a uniform interpretation scheme for the different views and beliefs of a diverse group of stakeholders. Beliefs and opinions of people from a different sociocultural status and educational background were equally valued and interpreted on the common theoretical ground provided by NPT. This ensured that all the voices of the different actors involved in migrant health were respected and fully exploited, which could also imply that the implementation project in each country reflected the diverse needs of local communities and was also highly representative of the local sociocultural contexts. The international comparisons were a strength of this study design. The generalisability of findings is limited because a qualitative case study approach was used. However, our finding that NPT was a relevant theoretical framework across international settings, including ones in which it had not been used before (ie, Greece, Austria, Netherlands), provides insight into transferrable issues across country settings.

In terms of rigour, there could be concerns that use of an a priori NPT coding framework could have resulted in data being 'shoehorned' into the theory, but as outlined earlier we actively searched for issues that lay 
outside the framework to ensure that this did not happen.

Finally, while we have a lot to say about engaging with multiple stakeholders and the value of their input, we provide no information on the effects of this participation on implementation outcomes as they were not the primary focus of this study. In addition, the voice of undocumented migrants was absent from our stakeholder groups and could have provided additional insights.

\section{CONCLUSIONS}

The focus of this research study was to explore if migrants and other key stakeholders make sense of the available G/TIs and can select one and engage with its implementation process in their local primary healthcare setting. From our findings, participatory approaches can be used at the outset of an implementation journey to enable migrants to work with other key stakeholders to select an intervention that makes sense in their local setting and that they will engage with and drive forward. Future comparative studies should explore the reproducibility of such methodologies in other regions of the world and, importantly, effects on uptake and usage of such G/TIs in practice and how this affects migrant healthcare experiences and well-being.

\section{Author affiliations \\ ${ }^{1}$ Faculty of Medicine, University of Crete, Heraklion, Greece \\ ${ }^{2}$ Department of Social Work, School of Health and Social Welfare, \\ Technological Educational Institute of Crete, Heraklion, Greece \\ ${ }^{3}$ Institute of Psychology, Health and Society, University of Liverpool, Liverpool, UK \\ ${ }^{4}$ Department of General Practice and Primary Care, Institute of Health \& Wellbeing, College of Medical, Veterinary and Life Sciences, University of Glasgow \\ ${ }^{5}$ Department of Primary and Community Care, Radboud University Medical Center, Nijmegen, The Netherlands \\ ${ }^{6}$ Pharos Centre of Expertise on Health Disparities, Utrecht, The Netherlands ${ }^{7}$ Faculty of Health and Medicine, Lancaster Medical School, Furness College, University of Lancaster, Lancaster University, Lancaster, UK ${ }^{8}$ Discipline of General Practice, School of Medicine, National University of Ireland, Galway, Ireland \\ ${ }^{9}$ Centre for Public Health, Medical University of Vienna, Vienna, Austria ${ }^{10}$ Graduate Entry Medical School, University of Limerick, Limerick, Ireland}

Contributors MP, AS, CL and AM led the write-up of this paper with input from all coauthors. All the authors contributed to the intellectual development of the proposal described and read and commented on drafts of this paper. They also read and approved the final manuscript.

Funding The RESTORE Project has received funding from the European Union Seventh Framework Programme (FP7/2007-2013) under grant agreement number 257258 .

Competing interests $A M, C A O$ and $C D$ are members of the international study group on NPT; MOdB and TdB are co-founders and co-directors of the Centre for Participatory Strategies, Co. Galway, Ireland.

Patient consent Obtained.

Ethics approval Obtained.

Provenance and peer review Not commissioned; externally peer reviewed.

Data sharing statement No additional data are available.

Open Access This is an Open Access article distributed in accordance with the Creative Commons Attribution Non Commercial (CC BY-NC 4.0) license, which permits others to distribute, remix, adapt, build upon this work noncommercially, and license their derivative works on different terms, provided the original work is properly cited and the use is non-commercial. See: http:// creativecommons.org/licenses/by-nc/4.0/

\section{REFERENCES}

1. Van den Muijsenbergh $\mathrm{M}$, van Weel-Baumgarten $\mathrm{E}$, Burns $\mathrm{N}$, et al. Communication in cross-cultural consultations in primary care in Europe: the case for improvement. The rationale for the RESTORE FP 7 project. Prim Health Care Res Dev 2014;15:122-33.

2. Council of Europe. Protocol No. 12 to the convention for the protection of human rights and fundamental freedoms. Strasbourg: Council of Europe, 2000.

3. Greenhalgh T, Voisey C, Robb N. Interpreted consultations as 'business as usual'? An analysis of organisational routines in general practices. Sociol Health IIIn 2007;29:931-54.

4. Flores $\mathrm{G}$. The impact of medical interpreter services on the quality of health care: a systematic review. Med Care Res Rev 2005;62:255-99.

5. Martin MC, Phelan M. Interpreters and cultural mediators-different but complementary roles. Translocations: migration and social change, special issue Migration and Health 2010;6. http://www. translocations.ie/volume_6_issue_1/index.shtml

6. Cochrane LJ, Olson CA, Murray $\bar{S}$, et al. Gaps between knowing and doing: understanding and assessing the barriers to optimal health care. J Contin Educ Health Prof 2007;27:94-102.

7. Larisch A, Oertel WH, Eggert K. Attitudes and barriers to clinical practice guidelines in general and to the guideline on Parkinson's disease: a national survey of German neurologists in private practice. J Neurol 2009;256:1681-8.

8. Lugtenberg M, Zegers-van Schaick JM, Westert GP, et al. Why don't physicians adhere to guideline recommendations in practice? An analysis of barriers among Dutch general practitioners. Implement Sci 2009;4:54.

9. Midlöv P, Ekesbo R, Johansson L, et al. Barriers to adherence to hypertension guidelines among GPs in southern Sweden: a survey. Scand J Prim Health Care 2008;26:154-9.

10. Taba P, Rosenthal M, Habicht J, et al. Barriers and facilitators to the implementation of clinical practice guidelines: a cross-sectional survey among physicians in Estonia. BMC Health Serv Res 2012;12:455.

11. McDonnell Norms Group. Enhancing the use of clinical guidelines: a social norms perspective. J Am Coll Surg 2006;202:826-36.

12. Fretheim A, Schünemann HJ, Oxman AD. Improving the use of research evidence in guideline development: 5 . Group processes. Health Res Policy Syst 2006;4:17.

13. Migration for development. A bottom-up approach. Join migration and development initiative: a handbook for practitioners and policymakers. European Union, 2010.

14. Greenhalgh T, Robert G, Macfarlane F, et al. Diffusion of innovations in service organizations: systematic review and recommendations. Milbank Q 2004;82:581-629.

15. Chowdhury AN, Banerjee S, Brahma A, et al. Participatory research for preventing pesticide-related DSH and suicide in Sundarban, India: a brief report. ISRN Psychiatry 2013;2013:427417.

16. Karliner LS, Jacobs EA, Chen $\mathrm{AH}$, et al. Do professional interpreters improve clinical care for patients with limited English proficiency? A systematic review of the literature. Health Serv Res 2007;42:727-54.

17. Hadziabdic E, Hjelm K. Arabic-speaking migrants' experiences of the use of interpreters in healthcare: a qualitative explorative study. Int $J$ Equity Health 2014;13:49.

18. Dahal G, Qayyum A, Ferreya M, et al. Immigrant community leaders identify four dimensions of trust for culturally appropriate diabetes education and care. J Immigr Minor Health 2014;6:978-84.

19. Hsieh E, Ju H, Kong H. Dimensions of trust: the tensions and challenges in provider-interpreter trust. Qual Health Res 2010;20:170-81.

20. O'Donnell CA, Higgins M, Chauhan R, et al. Asylum seekers' expectations of and trust in general practice: a qualitative study Br J Gen Pract 2008;58:870-6.

21. MacFarlane A, O'Reilly-de Brún M. An evaluation of uptake and experience of a pilot interpreting service in general practice in the HSE eastern region. Galway: National University of Ireland Galway, 2009.

22. Hadziabdic E, Heikkilä K, Albin B, et al. Problems and consequences in the use of professional interpreters: qualitative analysis of incidents from primary healthcare. Nurs Inq 2011;18:253-61.

23. Finch T. Teledermatology for chronic disease management: coherence and normalization. Chronic IIIn 2008;4:127-34. 
24. Bamford C, Heaven B, May C, et al. Implementing nutrition guidelines for older people in residential care homes: a qualitative study using Normalization Process Theory. Implement Sci 2012;7:106.

25. Greenhalgh T, Robb N, Scambler G. Communicative and strategic action in interpreted consultations in primary health care: a Habermasian perspective. Soc Sci Med 2006;63:1170-87.

26. MacFarlane A, O'Donnell C, Mair F, et al. Research into implementation strategies to support patients of different origins and language background in a variety of European primary care settings (RESTORE): study protocol. Implement Sci 2012;7:111.

27. May C, Finch T. Implementing, embedding and integrating practices: an outline of normalization process theory. Sociology 2009;43:535-54

28. Ajzen I. The theory of planned behavior. Organ Behav Hum Decis Process 1991;50:179-211.

29. Latour B. Reassembling the social: an introduction to actor-network-theory. Oxford University Press, 2005.

30. May CR, Mair F, Finch T, et al. Development of a theory of implementation and integration: Normalization Process Theory. Implement Sci 2009;4:29, p 4.

31. Chambers $R$. The origins and practice of participatory rural appraisal. World Dev 1994;22:953-69.

32. Grimshaw JM, Thomas RE, MacLennan G, et al. Effectiveness and efficiency of guideline dissemination and implementation strategies. Health Technol Assess 2004;8:1-72.

33. Simpson SH, Marrie TJ, Majumdar SR. Do guidelines guide pneumonia practice? A systematic review of interventions and barriers to best practice in the management of community-acquired pneumonia. Resp Care Clin N Am 2005;11:1-13.

34. Helfrich CD, Damschroder LJ, Hagedorn HJ, et al. A critical synthesis of literature on the promoting action on research implementation in health services (PARIHS) framework. Implement Sci 2010;5:16-7.

35. Shippee ND, Domecq Garces JP, Prutsky Lopez GJ, et al. Patient and service user engagement in research: a systematic review and synthesized framework. Health Expect 2015;18:1151-66.

36. O' Reilly de Brún M, MacFarlane A, de Brún T, et al. Involving migrants in the development of guidelines for communication in cross-cultural general practice consultations-a participatory learning and action research project. BMJ Open 2015;5:e007092.
37. Patton M. Qualitative evaluation and research methods. London: Sage, 1990.

38. de Brún T, de-Brún MO, van Weel-Baumgarten E, et al. Guidelines and training initiatives that support communication in cross-cultural primary-care settings: appraising their implementability using Normalization Process Theory. Fam Pract 2015;32:420-5.

39. O'Reilly-de Brún M, de Brún T. The use of participatory learning and action research in intercultural health: some examples and some questions. Migration Soc Change 2010;6:3.

40. May C, Murray E, Finch T, et al. Normalization Process Theory On-line Users' Manual and Toolkit. 2010. http://www. normalizationprocess.org (accessed11 Nov 2015)

41. Parsons JA, Baker NA, Smith-Gorvie T, et al. To 'Get by' or 'get help'? A qualitative study of physicians' challenges and dilemmas when patients have limited English proficiency. BMJ Open 2014;4: e004613.

42. May C. Towards a general theory of implementation. Implement Sci 2013;8:18

43. O Donnell CA, Burns N, Mair FS, et al., RESTORE Team. Reducing the health care burden for marginalised migrants: the potential role for primary care in Europe. Health Policy 2016;120:495-508.

44. Lau R, Stevenson F, Ong BN, et al. Achieving change in primary care-effectiveness of strategies for improving implementation of complex interventions: systematic review of reviews. BMJ Open 2015;5:e009993.

45. Jagosh J, Macaulay AC, Pluye $\mathrm{P}$, et al. Uncovering the benefits of participatory research: implication of a realist review health and research practice. Millbank Q 2012;90:311-46.

46. Morrison C, Dearden A. Beyond tokenistic participation: using representation artefacts to enable meaningful public participation in health service design. Health Policy 2013;112:179-86.

47. Mc Menamin R, Tierney E, MacFarlane A. Who decides what criteria are important to consider in exploring the outcomes of conversation approaches: a participatory health research study. Aphasiology 2015;29:914-38.

48. O' Reilly-de Brun M, de Brun T, Okonkwo E, et al. Using Participatory learning \& action research to access and engage with 'hard to reach' migrants in primary health care research. BMC Health Serv Res 2016;16:25. 